\title{
High-grade neuroepithelial tumor with medulloepithelioma-like areas out of the central nervous system in an infant with hemihypertrophy: a unique association
}

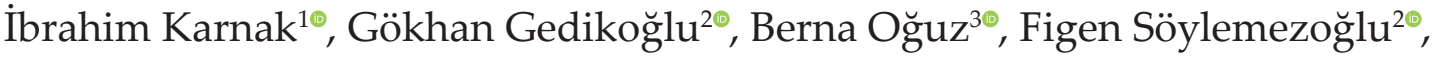 \\ Armita Bahrami $^{4 \oplus}$, Jason Chiang ${ }^{4 \oplus}$, Tezer Kutluk ${ }^{5 \bullet}$ \\ Departments of ${ }^{1}$ Pediatric Surgery, ${ }^{2}$ Pathology, ${ }^{3}$ Radiology and ${ }^{5}$ Pediatric Oncology, Hacettepe University Faculty of Medicine, Ankara, \\ Turkey; Department of Pathology, ${ }^{4}$ Division of Clinical Pathology, St. Jude Children's Research Hospital, Memphis, USA.
}

\begin{abstract}
Background. High-grade neuroepithelial tumor with areas resembling medulloepithelioma was diagnosed in an infant with coccygeal and inguinal masses. Hemihypertrophy is associated with Wilms tumor, hepatoblastoma and pancreatic tumors in children.

Case. The authors report on the first case of peripheral HNET associated with hemihypertrophy in an infant, with special discussion on histopathological differential diagnosis and management of this rare and highly malignant tumor.

Conclusions. HNET should be included into the list of hemihypertrophy associated tumors. Complete surgical excision with free margins is essential for the successful treatment of such cases and should be tried in suitable cases at the time of diagnosis. Continued treatment should be decided individually on a case to case basis.
\end{abstract}

Key words: high-grade neuroepithelial tumor, medulloepithelioma, inguinal, coccygeal, tumor, hemihypertrophy, infant.

The differential diagnosis of an inguinal mass in childhood include lymphadenitis, inguinal hernia with or without incarceration, spermatic cord cyst in boys and cyst of canal of Nuck that is its equivalent in girls, undescended testis, extravaginal testicular torsion and metastatic lymph node. Metastasis to inguinal lymph nodes may occur in lymphoma, rhabdomyosarcoma, testicular tumor and tumors of the sacrococcygeal area. Interestingly, we found a few cases with similar presenting locations which were diagnosed as peripheral medulloepithelioma but did not found a case with peripheral high-grade

$凶$ İbrahim Karnak

ikarnak@hacettepe.edu.tr

Received 18th February 2020, revised 21st May 2020,

accepted 26th May 2020. neuroepithelial tumor (HNET) associated with hemihypertrophy.

Hemihypertrophy is a predisposing abnormality for Wilms tumor and hepatoblastoma. The risk of Wilms tumor development is 3-4\% in children with hemihypertrophy. To the best of our knowledge, HNET or medulloepithelioma associated with hemihypertrophy has not been reported previously. ${ }^{1}$

Authors report on an infant with this unique association of peripheral HNET and hemihypertrophy, and make special emphasis on histopathological differential diagnosis and management of this rare and highly malignant tumor. 


\section{Case Report}

A 16-month-old boy was admitted for swelling in the right groin of one-week duration. It was painless, not enlarging and not disappearing. Past medical history was unremarkable except buried penis anomaly.

Physical examination revealed a firm, immobile, non-tender mass of $3 \times 4 \mathrm{~cm}$ size in the right groin. An additional mass of $3 \times 2.5 \mathrm{~cm}$ size was found located close to the coccyx. It was firm, fixed and not extending to the rectal wall on digital rectal examination. Femoral part of the right lower extremity was larger when compared to the corresponding proximal part of the left lower extremity and accepted as partial hemihypertrophy. Both testicles were normal on palpation and in the scrotum. The remaining findings on physical examination were normal.

Complete blood count (hemoglobin; $10.9 \mathrm{~g} /$ dl, leukocytes; 9300/ml, platelets; 346.000/ml) revealed mild anemia, blood biochemistry was in normal ranges. Alpha-fetoprotein level was mildly elevated (11.74 ng/ml, N: 0-9) and beta-human chorionic gonadotropin level $(<1.2 \mathrm{mIU} / \mathrm{ml}, \mathrm{N}<5)$ was within normal limit. Urine catecholamine metabolites levels (VMA; $12.86 \mathrm{mg} / \mathrm{g}$ creatinine, $\mathrm{N}<18.8$, HVA; 38.9 $\mathrm{mg} / \mathrm{g}$ creatinine, $\mathrm{N}<32.6$, 5-HIAA; $22.1 \mathrm{mg} / \mathrm{g}$ creatinine, $\mathrm{N}$ : 1.2-16.2) revealed mild elevation of HVA and 5-HIAA.

Ultrasound (US) examination of the inguinal region revealed a mass $(3.6 \times 2.7 \times 3 \mathrm{~cm})$ with solid and cystic component in the right groin. Neck and abdominal US showed normal findings. Magnetic resonance imaging (MRI) showed two similar masses with composed of cystic and contrast-enhanced solid areas in the right inguinal region and in the coccygeal region (Fig. 1). MRI also revealed that subcutaneous fat tissue and muscles of the right lower extremity was hypertrophic.

At surgery, coccygeal mass $(3 \times 2.5 \mathrm{~cm})$ was totally excised together with the coccyx (Fig. 2). The tumor mass was extending into the
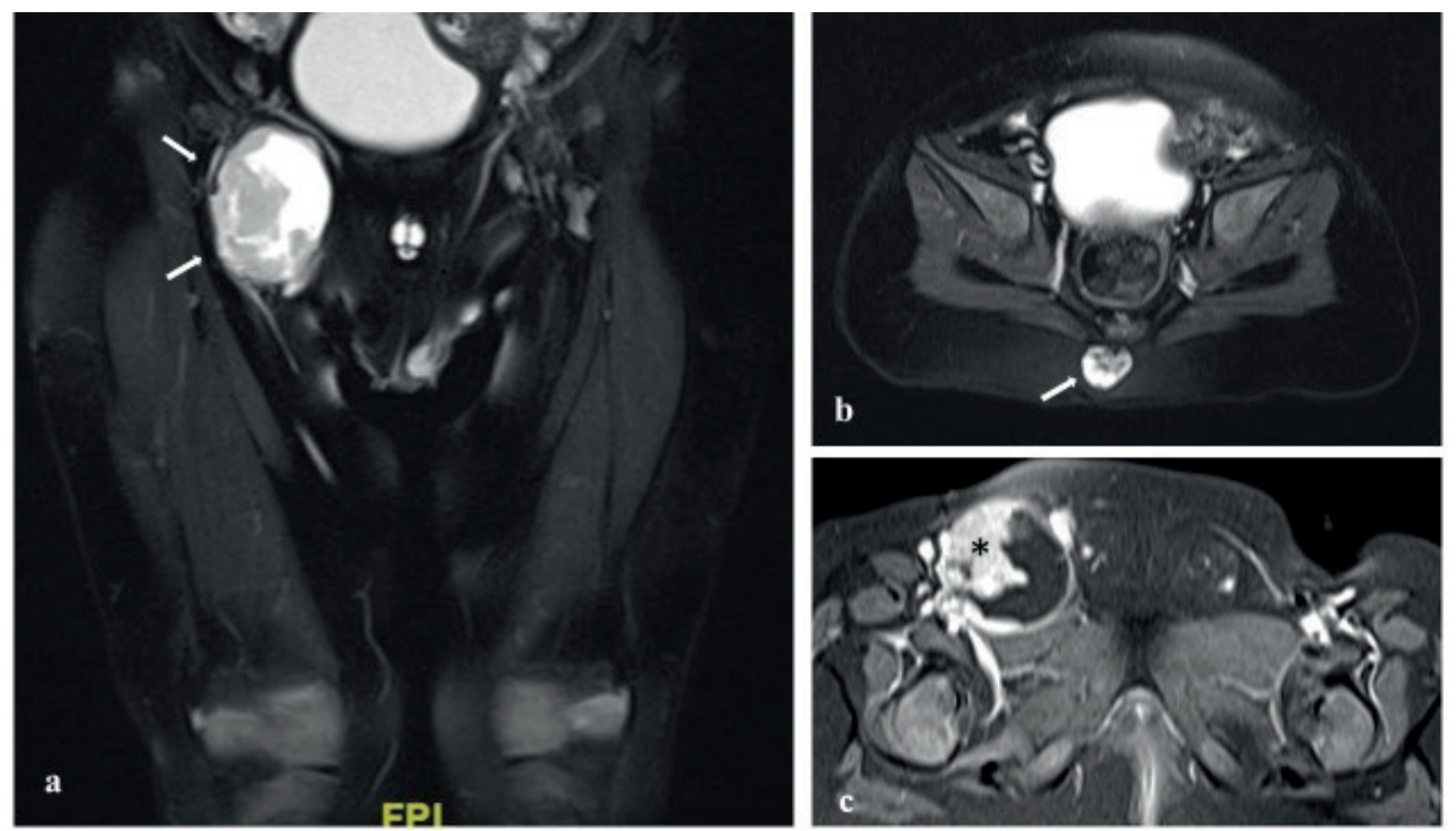

Fig. 1. Coronal (a) and axial (b) fat saturated T2-weighted MR images show radiologically similar masses (arrows) containing solid and cystic areas in the right inguinal region (a) and in the coccygeal region (b). Axial fat saturated post-contrast T1-weighted MR image (c) shows contrast-enhanced solid component $\left(^{*}\right)$ of the inguinal mass. 


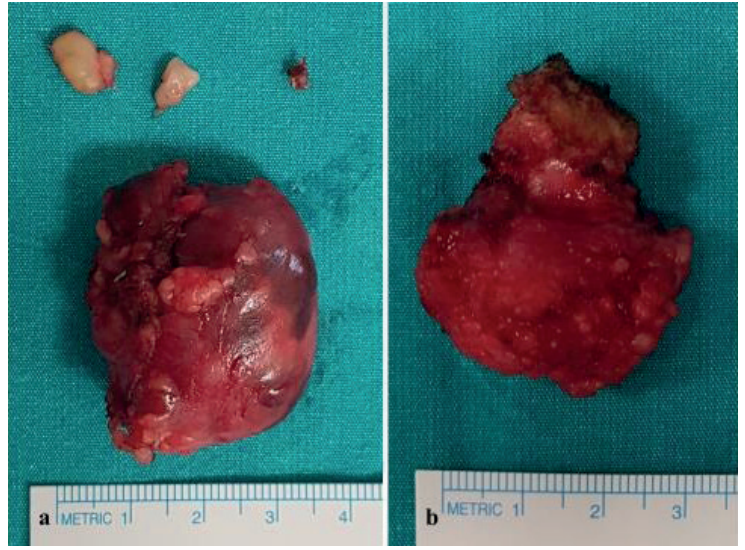

Fig. 2. Macroscopic view of inguinal tumoral mass with lymph nodes (a) and coccygeal tumoral mass (b).

gluteal muscles, well circumscribed and firm. The inguinal tumor mass was located in the femoral region, well circumscribed, firm and firmly attached to the great saphenous vein and femoral vein. The inguinal mass $(3 \times 4 \mathrm{~cm})$ was apparently larger than the coccygeal mass and it was totally excised including adjacent two lymph nodes (Fig. 2). The margins of both operative areas were marked with hemoclips. Postoperative course was complicated by wound infection in the coccygeal area. It was managed by antibiotics and intensive wound care and healed in a week.

Histopathological examination of coccygeal mass showed stellated/spindle cells arranged into cords or scattered individually, and epithelioid cells composed multi-layer rosettes or papilla in a myxoid background (Fig. 3). Neoplastic cells had monotonous appearance and contained nuclei with multiple nucleoli, and contained clear chromatin especially in tubular areas. Remnant of embryonal notochord was encountered in a focus in the cartilage tissue. Inguinal mass showed similar histopathological findings with coccygeal mass and neoplastic tubules displayed neural tube-like organization. Tubules contained marked pseudo stratification and apical mitotic activity. Neoplastic cells stained diffusely with PGP9.5, EMA, and SALL4; focally positive with GFAP, Glipican-3, CD56 and S100; and negative with OCT-3/4, WT1, pan-keratin, PLAP, alpha-fetoprotein (AFP) and CD30 (Fig. 4). Ki67 proliferation index reached to $50 \%$ by focally. Staining with SMARCA4, NSE and synaptophysin were not informative. Marked membranous staining with LIN28A was encountered in the apical region of multi-layered rosettes. Loss of INI1 was not encountered. Surgical margins were clear in both samples.

Histopathological material was consulted with extra institutional pathologists. They reported that the tumor had two distinct components: a low-grade component with glial and ganglion cell differentiation, which predominated in sections of the sacrococcygeal excision and
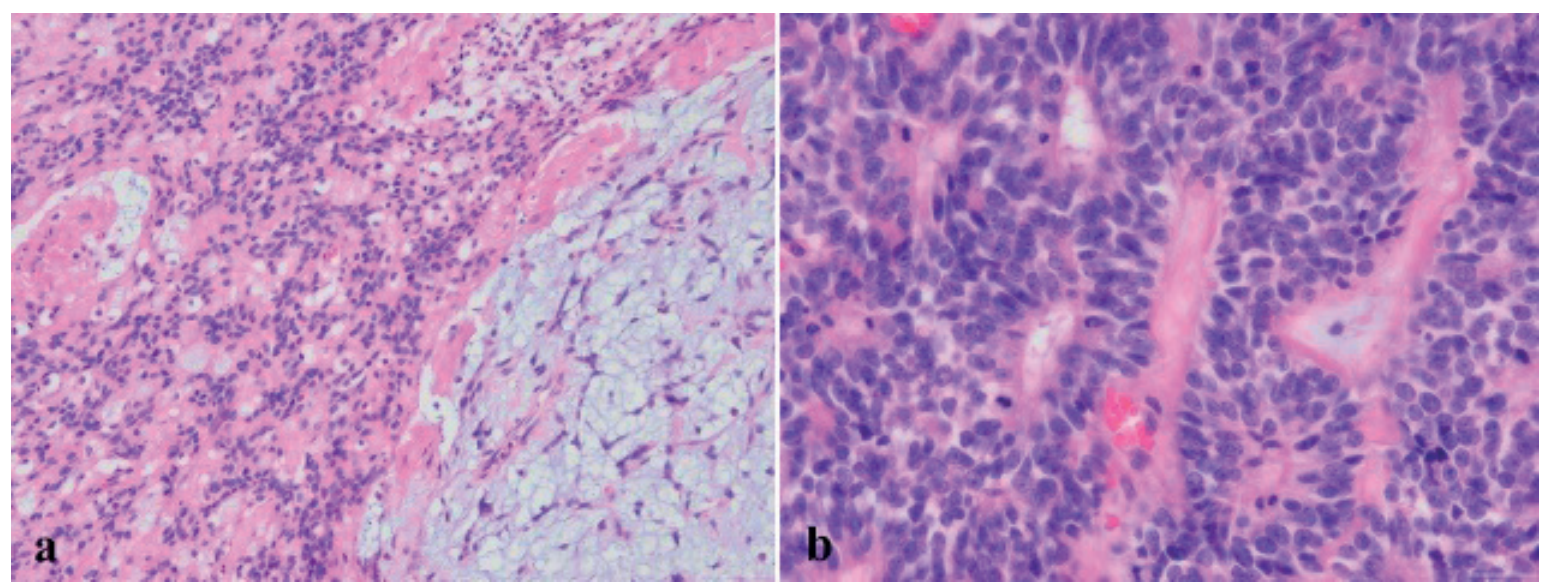

Fig. 3. Tumor cells showing diffuse infiltrative pattern (left side) and myxoid area (right side) (HE, X400) (a), tumor cells presenting rosette formation and mitotic figures (HE, x400) (b). 


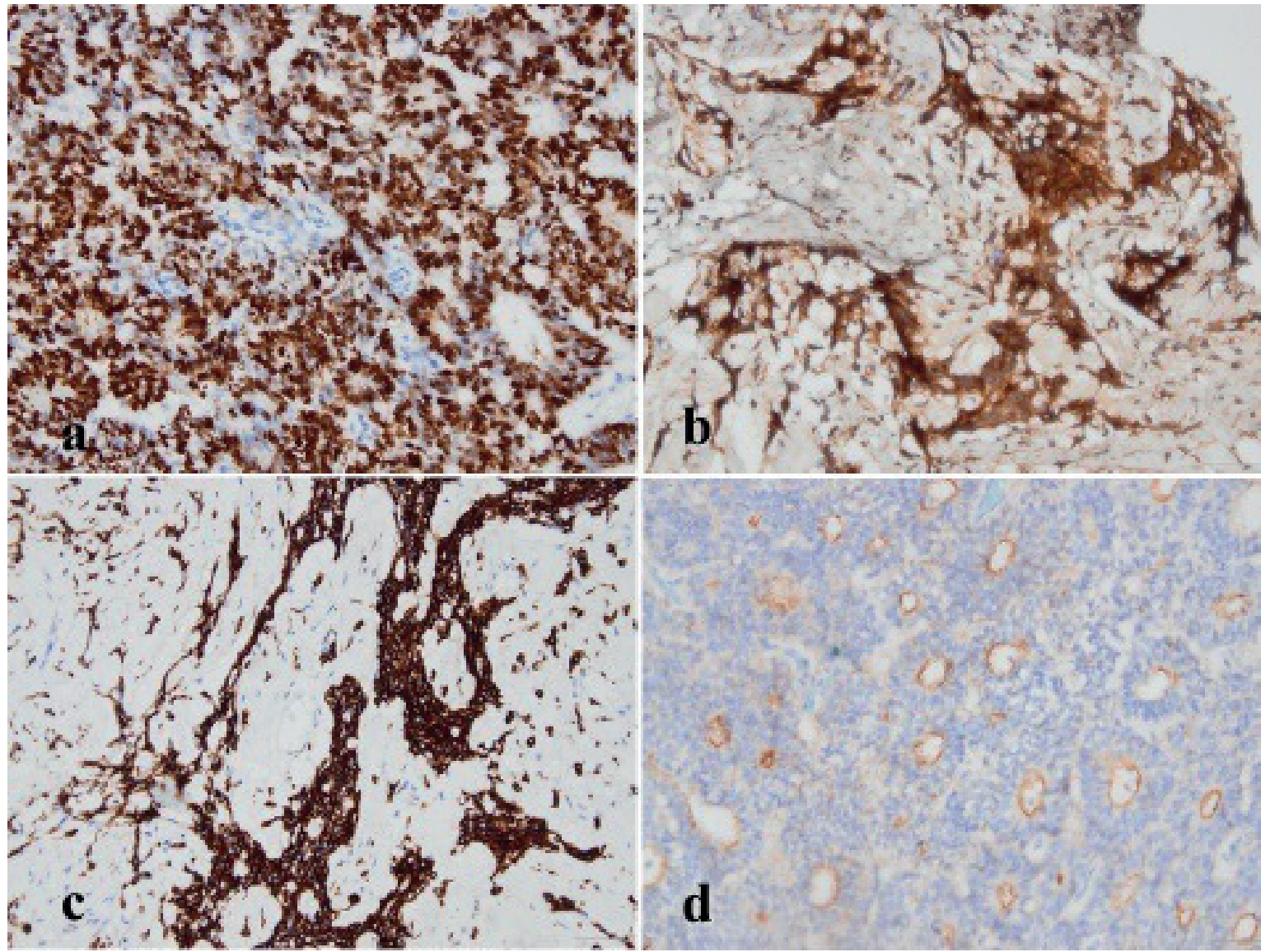

Fig. 4. Neoplastic cells showing nuclear staining positive with SALL4 (x200) (a), PGP9.5 (x100) (b), GFAP (x100) (c), and LIN28A (x100) (d).

characterized by monomorphic ovoid cells with low-grade nuclear atypia, low cellular density and low proliferation activity; and a high-grade neuroepithelial component, which was the predominant feature in the inguinal excision and characterized by hyperchromatic neuroepithelial cells with papillary and rosettelike structures. The presence of lymphoid tissue around the tumor in the inguinal resection suggested that this was the site of nodal involvement. Both resection margins were negative for tumor. FISH for chromosome 19 microRNA cluster (C19MC) (19q13.41) was negative for amplification. They made the diagnosis of HNET arising in a low-grade CNStype glioneural neoplasm for sacrococcygeal mass and metastatic HNET for the inguinal mass.
The child received 6 cycles of chemotherapy composed of Cisplatin and etoposide. Cisplatin was replaced by carboplatin to avoid toxicity and additional 2 cycles of carboplatin and etoposide were given. Control abdominal MRI in the $5^{\text {th }}$ and $11^{\text {th }}$ postoperative months showed postoperative signal changes in the inguinal and coccygeal areas without recurrent lesion. Late (postoperative $7^{\text {th }}$ month) PET revealed no activity in the paraaortic lymph nodes, inguinal area and inguinal lymph node but decreased activity in the coccygeal operative fields. The patient has been still under follow up without recurrent or metastatic disease for 18 months.

Informed consent was received from the family. 


\section{Discussion}

This case is an interesting case due to simultaneous presence of inguinal and coccygeal masses, challenges in the histopathological differential diagnosis and presence of associating hemihypertrophy.

Naturally, the histopathological differential diagnoses for a tumor in the coccygeal region would include a PNET-like teratomatous tumor as well as a myxopapillary ependymoma. Morphologically, however, the features do not fit well for either diagnosis. In addition, despite the diffuse expression of SALL4 in the high-grade component of the tumor, there were no teratomatous elements and no immunohistochemical expression of more specific germ cell tumor markers, such as PLAP, AFP, OCT3/4 (per initial pathological report) or OCT2. Both consultants of pathology believed that the morphological features were more in line with a CNS-type neuroepithelium than a peripheral neuroectodermal tumor, despite the lack of spinal canal connection. The possibility of an embryonal tumor with multilayered rosettes and medulloepithelioma has been raised. According to the consultant, the morphological features are not entirely classical for either entity. In addition, FISH for chromosome 19 microRNA cluster (C19MC) (19q13.41) was negative for amplification, providing no support for the diagnosis.

The histopathological findings of the tumor revealed morphological similarities to medulloepithelioma and embryonal tumor with multilayer rosettes, but negative for C19MC. Final diagnosis was given as HNET with areas resembling to medulloepithelioma.

Detailed search for simultaneous presence of inguinal and coccygeal masses has also led us to focus on a few cases of peripheral medulloepithelioma (Table I a and b). ${ }^{2-10}$

Medulloepithelioma is a rare embryonal tumor characterized by tubular and papillary patterns like primitive epithelium of the neural tube and medullary plate. It occurs usually in the eye or in the central nervous system and peripheral location has been reported quite rarely. Intraocular medulloepithelioma (diktyoma) is a benign tumor and complete excision is

Table Ia. Clinical characteristics of children with neuroepithelial tumor around the coccygeal region.

\begin{tabular}{|c|c|c|c|c|c|}
\hline $\begin{array}{l}\text { Case } \\
\text { no }\end{array}$ & Author, year & Age, sex & $\begin{array}{l}\text { Primary and metastatic } \\
\text { location(s) at presentation }\end{array}$ & $\begin{array}{l}\text { Tumor size } \\
(\mathrm{cm})\end{array}$ & Associated abnormality \\
\hline 1 & Seemayer $^{2}, 1975$ & $5.5 \mathrm{y}, \mathrm{F}$ & Presacral & $?$ & $?$ \\
\hline 2 & Nakamura $^{3}, 1982$ & Birth, M & $\begin{array}{l}\text { Course of sciatic nerve, dorsum } \\
\text { of right foot, right leg mass }\end{array}$ & $?$ & $?$ \\
\hline 3 & $\begin{array}{l}\text { Figarella-Branger }{ }^{4} \\
1992\end{array}$ & $17 \mathrm{y}, \mathrm{F}$ & Presacral & $?$ & $?$ \\
\hline 4 & Bruggers $^{5}, 1999$ & Term, F & Pelvic & NA & $\begin{array}{l}\text { Complete absence of left } \\
\text { hemipelvis and left kidney }\end{array}$ \\
\hline 5 & Donner $^{6}, 2003$ & $12 \mathrm{y}, \mathrm{F}$ & Pelvic & $\begin{array}{l}19 \times 9 \times 1.5 \\
19 \times 14 \times 9\end{array}$ & Not present \\
\hline 6 & Somjee $^{7}, 2004$ & $3.5 \mathrm{y}, \mathrm{M}$ & $\begin{array}{l}\text { Presacral, lung and liver } \\
\text { metastases }\end{array}$ & $5 \times 5 \mathrm{~cm}$ & Not present \\
\hline 7 & Pillai $^{8}, 2008$ & $3 y, F$ & Presacral, inguinal LAP & $6 \times 4.5 \times 3$ & Not present \\
\hline 8 & De Pasquale ${ }^{9}, 2014$ & $3 y, F$ & Presacral & $7 \times 6 \times 6$ & Not present \\
\hline 9 & Honnorat $^{10}, 2019$ & $2 y, F$ & Presacral & $6.3 \times 5 \times 5.7$ & Not present \\
\hline 10 & Karnak, 2019 & $16 \mathrm{~m}, \mathrm{M}$ & Coccygeal, inguinal LAP & $3 \times 2.5,3 \times 4$ & $\begin{array}{l}\text { Hemihypertrophy and } \\
\text { buried penis }\end{array}$ \\
\hline
\end{tabular}

Y: year, m: month, F: female, M: male, LAP: lymphadenopathy, NA: not available. 
Table Ib. Treatment and outcome in children with neuroepithelial tumor around the coccygeal region.

\begin{tabular}{|c|c|c|c|c|}
\hline $\begin{array}{l}\text { Case } \\
\text { no }\end{array}$ & $\begin{array}{l}\text { Histopathological } \\
\text { diagnosis }\end{array}$ & Treatment & Outcome & \\
\hline 1 & Medulloepithelioma & $\begin{array}{l}\text { Surgery, RT, CHT (after } \\
\text { metastases) }\end{array}$ & $\begin{array}{l}\text { Local recurrence and liver } \\
\text { metastases after } 2 \mathrm{~m}\end{array}$ & $\begin{array}{l}\text { DOD } 8 \mathrm{~m} \text { after } \\
\text { diagnosis }\end{array}$ \\
\hline 2 & Medulloepithelioma & Surgery (right hemipelvectomy) & $7 y$ & NED \\
\hline 3 & Medulloepithelioma & $\begin{array}{l}\text { Surgery, multiagent CHT and } \\
\text { RT (after metastases) }\end{array}$ & $\begin{array}{l}\text { Lung metastases } 6 \text { weeks } \\
\text { after surgery }\end{array}$ & $\begin{array}{l}\text { DOD } 8 \mathrm{~m} \text { after } \\
\text { diagnosis }\end{array}$ \\
\hline 4 & Medulloepithelioma & $\begin{array}{l}\text { Surgery (subtotal resection), } \\
\text { CHT }\end{array}$ & $50 \mathrm{~m}$ & NED \\
\hline 5 & Medulloepithelioma & $\begin{array}{l}\text { Surgery (2 times debulkings), } \\
\text { CHT }\end{array}$ & $2 \mathrm{y}$ & NED \\
\hline 6 & Medulloepithelioma & $\mathrm{CHT}$ & $8 \mathrm{~m}$ & On treatment \\
\hline 7 & Medulloepithelioma & $\begin{array}{l}\text { Surgery (total tumor and coccyx } \\
\text { resection, lymph node biopsy, } \\
\text { CHT, RT }\end{array}$ & $5 \mathrm{~m}$ & NED \\
\hline 8 & Medulloepithelioma & $\begin{array}{l}\text { Biopsy, CHT, Surgery (total } \\
\text { excision), RT }\end{array}$ & $\begin{array}{l}\text { Local recurrence } 6 \mathrm{~m} \text { later, } \\
\text { total reexcision, target } \\
\text { therapy }\end{array}$ & $\begin{array}{l}\text { DOD } 5 \mathrm{~m} \text { after } \\
\text { recurrence }\end{array}$ \\
\hline 9 & Medulloepithelioma & CHT, Surgery (total excision) & $5 y$ & NED \\
\hline 10 & $\begin{array}{l}\text { HNET containing } \\
\text { medulloepithelioma- like } \\
\text { areas }\end{array}$ & Surgery (total excision), CHT & $20 \mathrm{~m}$ & $\begin{array}{l}\text { Under follow } \\
\text { up }\end{array}$ \\
\hline
\end{tabular}

HNET: high-grade neuroepithelial tumor, CHT: chemotherapy, RT: radiotherapy, DOD: died of disease, NED: no evidence of disease.

frequently enough for cure. In contrast, CNS medulloepithelioma is an aggressive neoplasm and good prognosis is possible only in cases with complete excision of the tumor. ${ }^{11}$

Our case with the diagnosis of peripheral HNET has unique features such as the larger size of the inguinal metastasis than coccygeal primary neoplasm and the presence of hemihypertrophy. Hemihypertrophy is an alarming finding on physical examination and prompts urinary and hepatobiliary evaluation by ultrasound for Wilms tumor and hepatoblastoma respectively. ${ }^{1}$ Hemihypertrophy may also associate with benign lipomatous tumors in children. ${ }^{12}$ Although the exact mechanism could not be established, HNET should be included in the list of neoplasms associated with hemihypertrophy. The larger size of inguinal metastasis may be also explained by the increased blood flow to the right inguinal area along with hypertrophied proximal part of the right lower extremity.
The tumor location close to the coccyx may be due to tumor origin of multipotent cells located around the coccygeal region in the embryological life. There was no tumoral mass in presacral and abdominopelvic regions by detailed radiological examination, which is also an interesting finding in this patient.

HNET is a malignant tumor and may metastasize to the inguinal lymph nodes. The authors agree that complete excision of the tumor should be tried in suitable cases (no distant metastasis, no possibility of increased surgical morbidity). Multiagent chemotherapy is necessary for the treatment of peripheral HNET. Close follow up is essential as the clinical course is difficult to predict. One may argue the need of radiotherapy in such a case. The authors decided not to give radiotherapy in this case with safe surgical margins and potential side effects of radiotherapy in two different locations. 
The authors presented a unique case of peripheral HNET in an infant with hemihypertrophy. HNET should be included into the list of hemihypertrophy associated tumors. Complete surgical excision with free margins is essential for the successful treatment of such cases and should be tried in suitable cases at the time of diagnosis. Decision making on the treatment of such cases are difficult due to rarity of the disease. We believe surgery, multiagent chemotherapy and radiotherapy must be decided individually in each case, then close follow up is necessary.

\section{REFERENCES}

1. Kalish JM, Doros L, Helman LJ, et al. Surveillance recommendations for children with overgrowth syndromes and predisposition to Wilms tumor and hepatoblastoma. Clin Cancer Res 2017; 23: e115-e122.

2. Seemayer TA, Thelmo WL, Bolande RP, Wiglesworth FW. Peripheral neuroectodermal tumors. Perspect Pediatr Pathol 1975; 2: 151-172.

3. Nakamura Y, Becker LE, Mancer K, Gillespie R. Peripheral medulloepithelioma. Acta Neuropathol 1982; 57: 137-142.

4. Figarella-Branger D, Gambarelli D, Perez-Castillo M, Gentet JC, Grisoli F, Pellissier JF. Ectopic intrapelvic medulloepithelioma: case report. Neuropathol Appl Neurobiol 1992; 18: 408-414.
5. Bruggers CS, Welsh CT, Boyer RS, Byrne JL, Pysher TJ. Successful therapy in a child with a congenital peripheral medulloepithelioma and disruption of hindquarter development. J Pediatr Hematol Oncol 1999; 21: 161-164.

6. Donner LR, Teshima I. Peripheral medulloepithelioma: an immunohistochemical, ultrastructural, and cytogenetic study of a rare, chemotherapy-sensitive, pediatric tumor. Am J Surg Pathol 2003; 27: 1008-1012.

7. Somjee S, Craver R, Kallagowdar C, Yu LC. Presacral medulloepithelioma - de novo or teratomatous? Pediatr Hematol Oncol 2004; 21: 85-91.

8. Pillai SB, Kumar RK, Ganesan PA, Nirmala V. Presacral medulloepithelioma. Indian $\mathrm{J}$ Pathol Microbiol 2008; 51: 444-445.

9. De Pasquale MD, De Ioris MA, Gallo A, et al. Peripheral medulloepithelioma: a rare tumor with a potential target therapy. J Translat Med 2014; 12: 149.

10. Honnorat M, Al-Karmi S, Hawkins C, et al. Presacral medulloepithelioma: case report and literature review. J Pediatr Hematol Oncol 2020; 42: 244-247.

11. Molloy PT, Yachnis AT, Rorke LB, et al. Central nervous system medulloepithelioma: a series of eight cases including two arising in the pons. J Neurosurg 1996; 84: 430-436.

12. Boybeyi O, Alanay Y, Kayikçioglu A, Karnak I. Hemihyperplasia-multiple lipomatosis syndrome: an underdiagnosed entity in children with asymmetric overgrowth. J Pediatr Surg 2010; 45: E19-E23. 